\title{
Fit for School: The Samurai School Program
}

\author{
Thomas Wernicke, MD, and Karin Kalbantner-Wernicke, LpaedPT ${ }^{2}$
}

\begin{abstract}
For the past several years, an increasing number of schools across Europe have been using the Samurai School Program successfully. In 2015, it was also introduced in the United States with great acceptance. The program is aimed at treatment of children on the autistic spectrum, including those with attention-deficit hyperactivity disorder or similar disorders. Given that such children lack social skills and may be prone to violence, treating this disorder is of concern. The objective of the Samurai School Program is to address social and violent tendencies in youth.
\end{abstract}

Key Words: Samurai School Program, Samurai Shiatsu, Perception, Proprioception, Respect, Self-Efficacy, Social Competences, Meridian Development

\section{INTRODUCTION}

$\mathbf{O}$ VER THE PAST FEW YEARS in European countries, there has been an observable trend of teachers worrying about bad classroom atmosphere and looking for solutions to this problem. One way of improving the situation is to use the Samurai School Program. After generally positive experiences among teachers and students, this program is being implemented at an increasing number of schools in several countries. The program was officially introduced in the United States during the 2015 American Academy of Medical Acupuncture (AAMA) Annual Symposium, in St. Louis, $\mathrm{MO}$, and the overall concept was met with great acceptance. In the same year, the first train-the-trainer session was held in St. Petersburg, FL. The objective of this article is to explain this increased interest in the Samurai School Program.

The answer can be found by reviewing the daily practice of a pediatrician. The main reasons that patients ages 6-12 enter into pediatric treatment include issues with poor posture, short concentration and attention spans, and poor social behavior. To take corrective-yet nonmedicinal-action, the pediatrician will prescribe physical therapy, occupational therapy, osteop- athy, psychotherapy, etc. However, there are problems with these kinds of therapies. One of the great disadvantages lies in the following: By undergoing one of these therapies, affected children will automatically be pathologized and will consequently develop a feeling of not being acceptable as they are.

Yet, many cases of poor posture, short concentration and attention span, and deficient social behavior do not result from underlying pathology. In many cases, a significant number of children are delayed in their development-resulting from a lack of physical activity and/or lack of access to new technology. Hence, the Samurai School Program focuses on developmental delays by promoting exercise, posture improvement, and student focus during ages of 6-12, using materials at hand instead of unavailable digital technology. In a very simple way, this program promotes health and improves the ability to concentrate.

\section{PHYSICAL ACTIVITY AS AN EXPRESSION OF COMMUNICATION}

Before a child has mastered the use of verbal language, movements are the primary and most important way of

\footnotetext{
${ }^{1}$ International Society for Traditional Japanese Medicine and Therapeuticum Rhein-Main, Hochheim, Germany.

${ }^{2}$ Promotional Organization Samurai-Program and Therapeuticum Rhein-Main, Hochheim, Germany.

(C) Thomas Wernicke and Karin Kalbantner-Wernicke, 2016; Published by Mary Ann Liebert, Inc. This Open Access article is distributed under the terms of the Creative Commons Attribution Noncommercial License (http://creativecommons.org/licenses/by-nc/4.0/) which permits any noncommercial use, distribution, and reproduction in any medium, provided the original author(s) and the source are credited.
} 
communicating and means to satisfy the need for interaction with other individuals. This, in turn, is expression of the high significance of physical activity. Until the age of 8 , a child interacts with and accesses the environment through movements. An ability closely related to movement is also used-perception. Perception is a requirement for both children and adults to react and communicate as well as dealing with their environments.

\section{MERIDIAN DEVELOPMENT}

Perception is not a phenomenon of isolated instances. Most situations in everyday life require different fields of perception to be activated simultaneously. Particularly, for child development, these fields of perception are of considerable significance. In this respect, the tactile, proprioceptive, and vestibular systems - the basic senses-play a key role. In the context of meridians, these basic senses are attributed to particular groups of meridians. Although the meridians of every separate group are still undergoing development in children, these meridians, nonetheless, seem to be the pacemakers of child development. It can be assumed that the meridians are only completely developed or matured with the completion of puberty. How does the maturing of a meridian look? The current authors have developed the Model of Energetic Development over the past 3 decades. ${ }^{1}$

The Model of Energetic Development states that, just like the motor and sensory systems, the energetic system (and, hence, the meridians) is not yet fully developed at the time of birth. Just as with motor and sensory development, maturing of the meridians happens gradually. Therefore, stimuli are needed that the not-yet-specified meridians react to in different ways-or perhaps do not react to at all.

\section{The Three Groups of Meridians}

Maturing of the meridians happens as follows: Initially, during the first year of life, the potential 12 main meridians

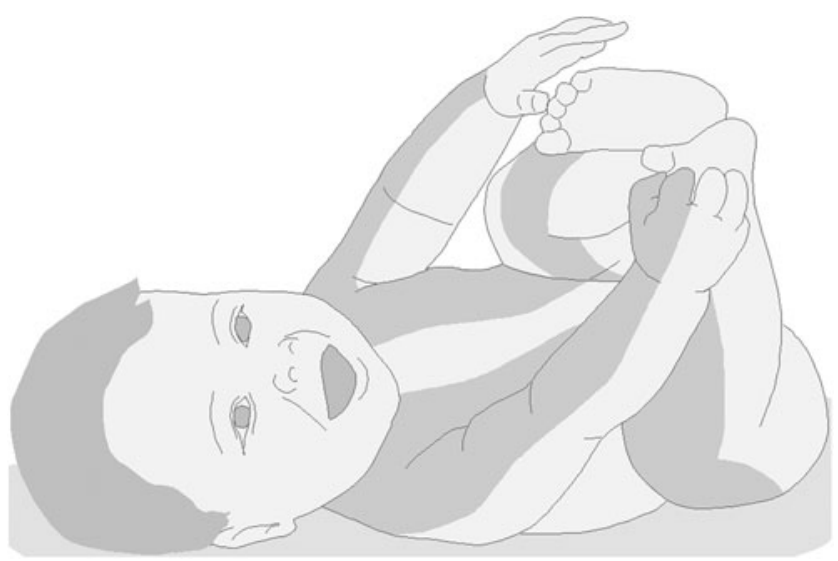

FIG. 1. Meridian group of the front, shown in shaded areas.

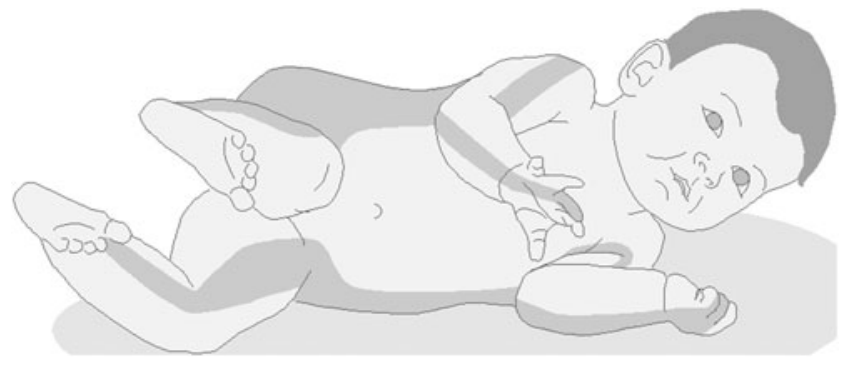

FIG. 2. Meridian group of the side, shown in shaded areas.

are in 3 groups. Each group consists of 4 not-yet-fully-matured meridians already working together closely. The maturing meridians Lung, Large Intestine, Spleen, and Stomach form the group of the front of the body. To the side group belong the Pericardium, Triple Energizer, Liver, and Gall Bladder meridians. The group of the back of the body consists of the Heart, Small Intestine, Kidney, and Bladder meridians.

These three groups differ in their efficacy (i.e., every group has a developmental and life-related topic).

\section{Developmental and Life-Related Topics}

The meridian group of the front (Fig. 1) contains the impulse to find one's center. This concerns motor as well as emotional states. Furthermore, experiencing and feeling limits and borders as well as those of others belongs to the aspects of this group. The basic sense attributed to the meridian group of the front is touch (tactile perception; Fig. 1).

The meridian group of the side (Fig. 2) is responsible for rotation. These motor and coordinative forms of movement are the bases of most everyday movements of the human organism. Flexibility and coordination on all levels (from falling securely to mental flexibility to maneuvering successfully through life) are based on the bodily and/or mental ability to rotate. The basic sense attributed to the

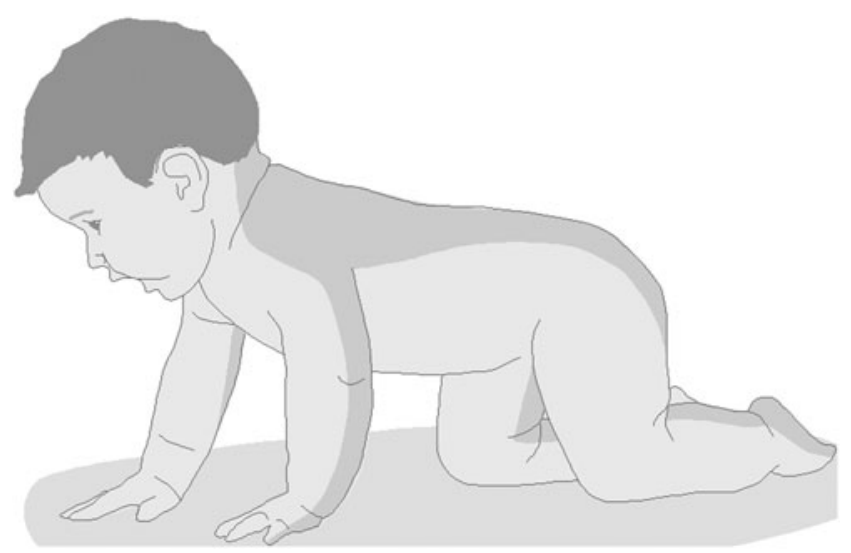

FIG. 3. Meridian group of the back, shown in shaded areas. 
meridian group of the side is the sense of balance (vestibular system; Fig. 2).

The meridian group of the back (Fig. 3) embraces the infantile developmental step from resting on the arms when lying on the stomach to becoming a quadruped in later childhood. In adults, the process of getting up when in bed (mentally: "I need to get up!"; physically: "sit up and get up on my feet") is a quality of the meridian group of the back. Hence, an associated quality is the impulse for inner and outer uprighting, which is rooted here. The basic sense attributed to the meridian group of the back is the perception of depth (proprioceptive system; Fig. 3).

It is easily observable that the still-maturing meridians form a communication network between the child and his or her environment. Via this connection, they allow for the integration of reflexes and stimuli, which means that these meridians are also responsible for posture, movement, and patterns of personality and behavior. Knowledge of this interrelation of motor, sensory, and energetic levels enables a new perspective on child development, potentially resulting in specific approaches.

The Samurai School Program has a particular focus on the meridian group of the back. Next to the alreadymentioned aspects of inner and outer uprighting, and perception of depth, this group is associated with the following developmental and life topics:

- Ability to concentrate

- Posterior differentiation

- Ability to listen

- Development of language and speech

Many children are not given the opportunity to allow for the meridians of the posterior group to mature fully. Needed stimuli are missing (e.g., lacking time spent on the stomach as infants because of parental fears of sudden infant death syndrome). Later on, from ages 3-6, home and school environment do not always provide opportunities to exercise and move around.

The objective of the Samurai School Program is to support the meridian groups in their maturing process. Thereby, children can be enabled to develop skills that are highly necessary for success in school.

\section{DEVELOPMENT OF THE SAMURAI SCHOOL PROGRAM}

For the past 30 years, both authors of this article have been laying their professional focus on children and have established the child center Therapeuticum Rhein-Main, in the heart of the Rhein-Main area near Frankfurt, Germany. In this center, both allopathic (Western medicine) as well as SinoJapanese pediatric diagnostics and therapies are practiced.

In the context of their fieldwork in schools, the current authors noticed, particularly during the last 2 decades, that some students were (1) lacking proprioception and/or (2) lacking social competences.

These two are key elements to the development of the Samurai School Program.

\section{Lacking Proprioception}

In school, a lack of proprioception manifests as, for example, continuous fidgeting. A cause for this permanent restlessness can be a lack of body awareness-not being able to feel oneself sufficiently - which, in many cases, will lead to postural issues. The response of the human body may be delayed. Extended periods of sitting can result in back and/or headache pain or a general feeling of not being well. To counteract this, students may be forced to "fight" with their postures, which manifests as fidgeting. As such, energy and attention are directed to these students' pain and not to their studies. The serious consequence is attention deficit hyperactivity disorder (ADHD) leading to higher rates of ADHD labeling of children.

The opposite would be an actual presence of body awareness, which is a requirement for self-awareness (i.e., students feel that they are moving and know which stimuli are flooding their senses, and these students are thereby able to receive information within their bodies). All this is processed with the proprioceptive system-a term stemming from Latin, meaning "to take possession of oneself" (proprium means "one's own"; capere means "to take possession of"). By perceiving their own selves from the inside, students find and take possession of themselves.

\section{Lacking Social Competences}

Insufficient body awareness in students can lead to a lack of awareness and respect for personal and other students' limits and borders. The situation in a classroom community can escalate further into prejudice if the students are in an unfamiliar environment. Prejudice is in many cases related to difference in skin complexion as well as cultural background and/or religion.

These observations and thoughts were the leading motivators for developing the Samurai School Program. The key question behind the concept concerned how an efficient learning situation can be established. In this respect, the following 3 aspects were of significance. The students should:

(1) Feel comfortable in togetherness

(2) Be respected and acknowledged for all their differences, regardless of social and cultural background

(3) Feel what it is that makes every individual in the classroom community (and hence themselves as well) feel good and with what other students can be supported

Furthermore, the Samurai School Program incorporates the topic of "self-efficacy," dealing with the question 
concerning what individual students can do in challenging situations, such as anxiety before a test, to help themselves? The program offers helpful and age-appropriate tips and tricks (e.g., massaging the acupuncture point PC 8 with the help of a "magic stone").

\section{THE SAMURAI SCHOOL PROGRAM MODULES}

To achieve improvement in proprioception, social competences and respect, acknowledgement, and self-efficacy, the Samurai School Program includes the following modules:

- Treatment sequence of Samurai Shiatsu

- Exercises

- Interesting facts about Japanese culture

Prior to going deeper into the Modules the term samurai and why it was chosen as the name of the program is now explained. The term samurai carries the meaning of "servant," "companion," and "protector." As the name given to the Samurai School Program, this name also stands for braveness, strength, and health, as well as for attentive dealing with other people and with and oneself. ${ }^{2}$ As the students learn in the course of the program, this meaning differs widely from what they usually think of when they hear the word samurai. They would usually associate it with "fighting like ninjas." Yet, it is exactly this misunderstanding that catches the students' attention-especially boys-and pulls them in.

The content of the Samurai School Program is embedded in a story about two fictional characters-Japanese samurai students Kooko and Hanako. The storyline and complementary pictures are appealing to boys and girls of different cultural backgrounds (Fig. 4). It is easy for participating children to identify with the characters not last because the children learn that, in Japan, there were both male and female samurai. Because the story takes place long ago and is geographically far away in an era completely different from what the students know (Japan, 200 years ago), their curiosity is accompanied by a certain fascination for things that are "strange." 3

By letting every child, regardless of cultural background, engage in playing the role of a samurai, the Samurai School Program introduces the child to what is "strange" and encourages him or her to try something new without inducing resistance or prejudice. The higher the degree of identification during the play and exercise sequences, the better each participant can experiment with this opportunity and his or her abilities, which then can lead to facilitating access to behavior-changing components of the program, gained from the experience itself. ${ }^{4}$

Another important aspect is the potential for supporting children with motor challenges to integrate into the group more easily. This is accomplished by allowing each child to

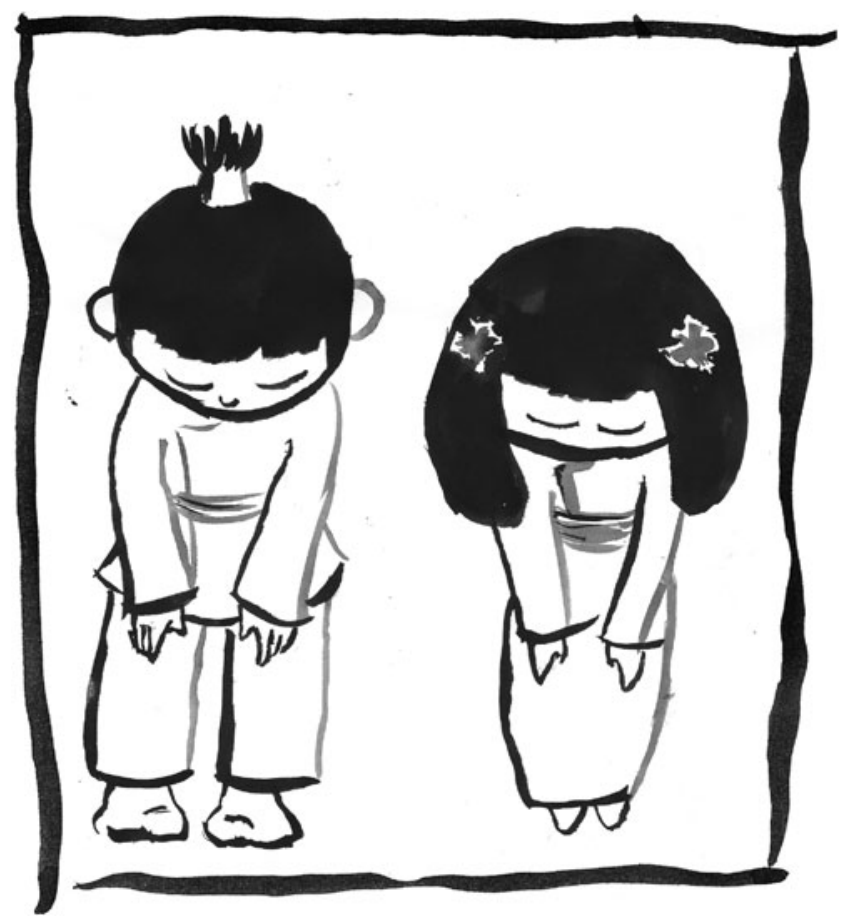

FIG. 4. Kooko and Hanako.

identify with the role as a samurai-the exercises are not about motor skills but are much more about living up to the role and sense of purpose of a samurai.

\section{Samurai Shiatsu}

The world is in need of geniuses with igniting minds and ideas. This, however, requires individuals working together as a team, and teamwork already begins in school where students have to learn to deal with, and approach each other, adequately. Through respectful touching and being touched as well as through joint moving exercises, the spirit of teamwork is fostered.

The Samurai School Program trains the students' movements, posture, and perception. The program's clear structure enables students to perform, effectively and self-sufficiently, the introduced exercises after only three sessions (equivalent to three school periods). The main part of the program is the Samurai Shiatsu, which stems from the actual Japanese Shiatsu, a manual treatment technique based on the teachings of meridians. To make the concept of Shiatsu fit for school, it is tailored to the respective age range of children so they can treat each other after investing a minimal amount of time.

To the basic principles of Shiatsu, and hence also of Samurai Shiatsu, belong a respectful conduct/dealing with each other and preserving one's own limits and borders as well as those of other people. Therefore, rules play a fundamental role. To help students learn to accept rules, the program is based on rituals and play. One example is bowing to each 
other at the beginning and end of each sequence to help participants playfully gain acceptance of rules.

Respectful conduct and dealing with each other is practiced by asking the obligatory question "may I touch you?" before using Samurai Shiatsu on another student. Furthermore, throughout the treatment, many times, the practicing student will ask the one he or she is practicing on about his or her well-being and needs. Thereby, the treated student is supposed to gain a feeling for his or her own needs and learn to express them.

At the same time, the treating student learns about other students' limits and borders and, at the same time, to respect them. This allows (also restless) children who have difficulty with knowing and applying their own strength adequately to apply touch consciously and attentively. At the end of every treatment, the treating student thanks the one who was practiced on.

\section{Implementation of the Samurai School Program}

In the story woven around the program, the samurai students Kooko und Hanako are given the following homework one day:

(1) For future samurai, it is important to be healthy and strong. Think of something to keep your back healthy and strong.

(2) Find tricks to help you focus and learn better in school.

Based on these two tasks, the current authors (as alias Kooko and Hanako) developed the treatment sequences and exercises as part of the Samurai School Program. The key element here is imparting knowledge of Samurai Shiatsu, which is supposed to be practiced once per week for 30-45 minutes for 3 weeks.

During that initial time, both students and teachers are instructed by a specialized trainer when learning and practicing the treatment techniques. There is no need for rearranging desks or chairs or making other preparations. Samurai Shiatsu is always practiced on the fully dressed body. A complete sequence takes a maximum of 8 minutes per child.

\section{Example of Two Treatment Sequences}

This is how Samurai Shiatsu is actually practiced:

A treated student is sitting on a chair while the treating partner stands behind it. With the question, "may I touch you?," the treating student seeks permission to get in physical contact with the treated student. The treating student then rubs his or her hands until they are warm and places them on the shoulders of the treated student (Fig. 5).

This is the first treatment sequence in Samurai Shiatsu and called Samurai Warming in the Sun. The treating student asks if the sun is shining warmly enough; in case it is not, the student's hands will be rubbed against each other again to create more heat. The objective of this first se-

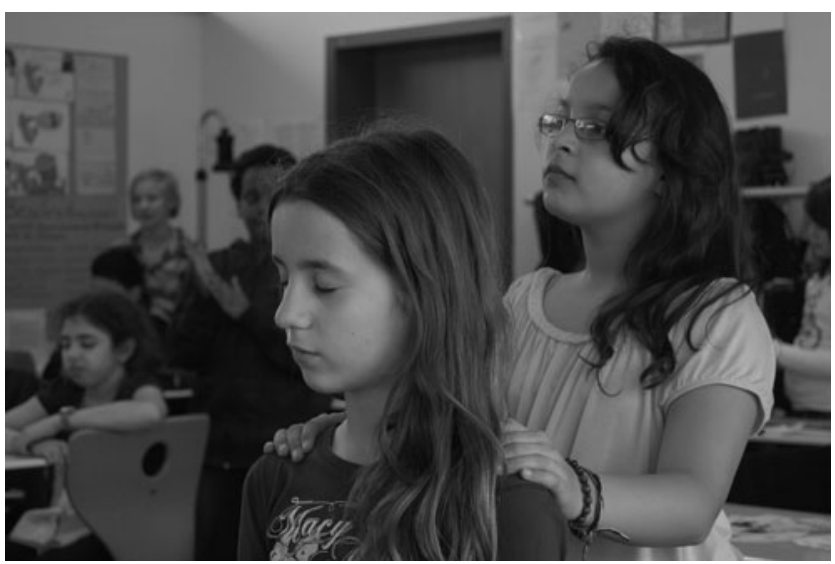

FIG. 5. Samurai Warming in the Sun.

quence is getting in contact, deepening self-awareness, stimulating of $k i$ (in Chinese, Qi).

Another sequence is called Samurai, Bear, and Tiger Meet. For this sequence, the hands of the treating student wander on both sides of the treated student's spine (the Bladder meridian) from the top to the bottom like bear claws (Fig. 6). From the bottom to the top, however, the hands move softly, like tiger paws, directly on the spine (Dumai). Objectives (all are also functions of the Bladder Meridian) of this treatment sequence are improving depth perception in the back, waking up, increasing feeling for borders of the back, improving posture/uprighting, and improving ability to concentrate.

\section{Effects of Samurai Shiatsu on the Treated Student}

Performing Samurai Shiatsu does not only treat the student it is performed on but also has an effect on the student who is performing it.

The close connections among hand, mouth, and tongue motor have been used by occupational and speech therapists. Samurai Shiatsu also applies this knowledge and is

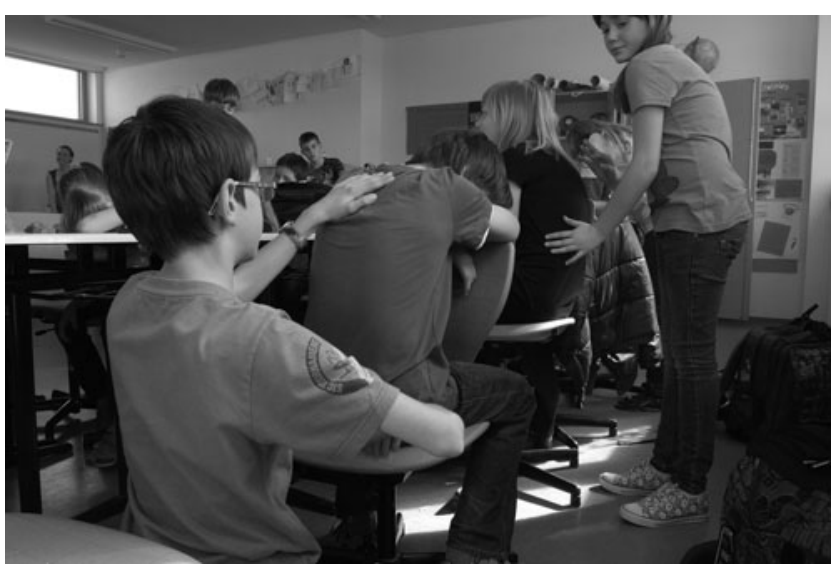

FIG. 6. Samurai, Bear, and Tiger Meet. 


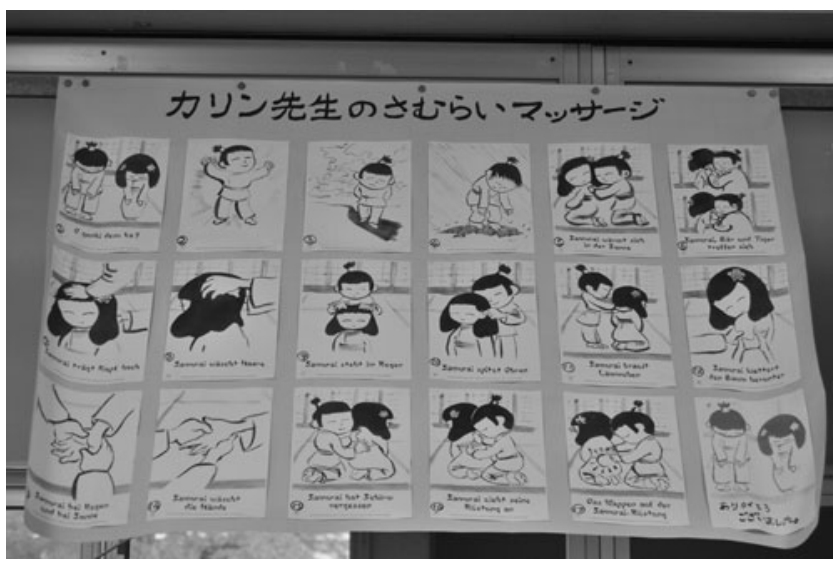

FIG. 7. Kooko and Hanako arrive in Japan.

designed to make treating students perform many different hand movements. Thereby, these movements support mouth and tongue control, which also affects speaking skills positively.

Yet, finger exercises do not only make the hands more flexible but also promote circulation in the brain because of an existing hand-brain connection, which will also lead to improvement of retentiveness and short-term memory.

\section{Scientific Research Regarding the Samurai School Program}

Compared to adults, children have a major advantage because they are still growing: The faster a child grows, the more sensitively the child's locomotor and nerve system react to stimuli from touch and movement (the MarkJansen-Law). ${ }^{5}$ This carries both risks and opportunities. The risks are continuous incorrect weight bearing or bullying situations - physically or psychologically challenging - that can lead to damaging body and soul. The opportunities (compared to adults) are well-dosed and respectfully performed touching — as required during the Samurai School

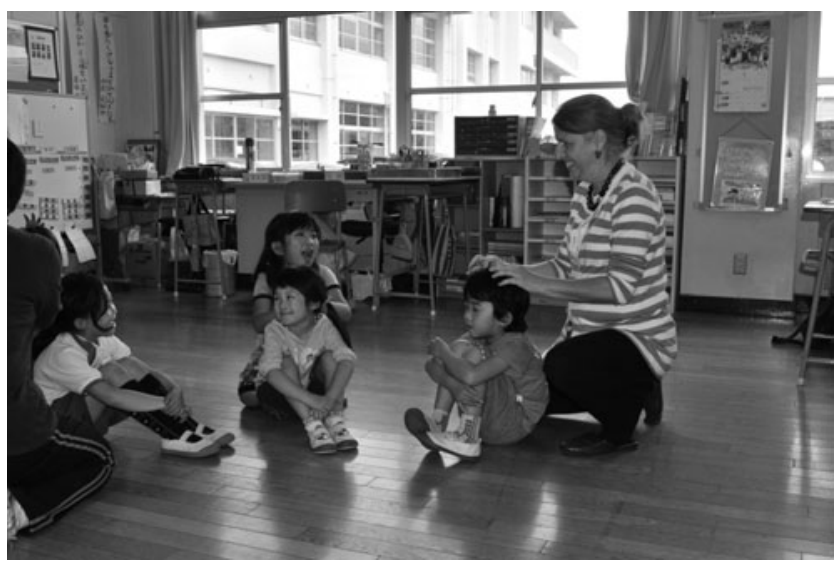

FIG. 8. Author, Karin Kalbantner-Wernicke, in a Japanese elementary school.

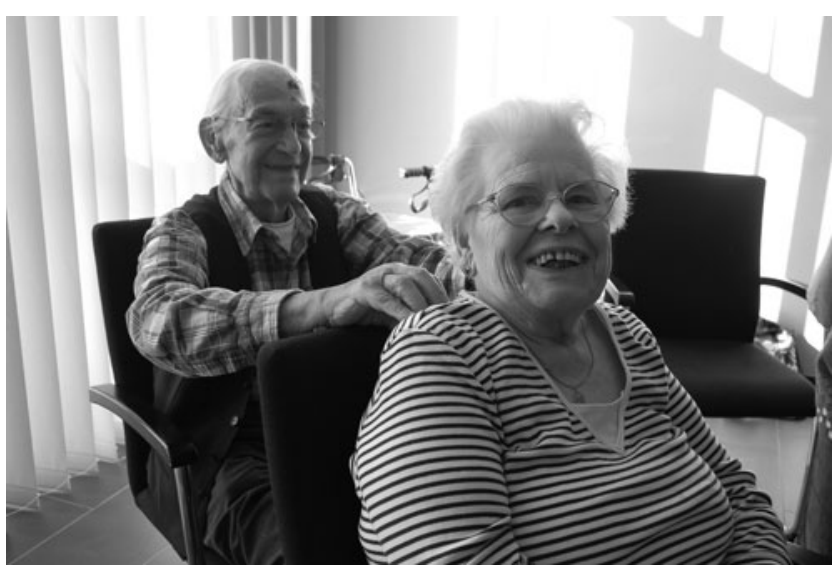

FIG. 9. Sprightly Samurai.

Program - that offer exercise with stimuli that affect the child in a highly positive fashion and support positive interaction with other people.

Since 2013, the Samurai School Program has been scientifically followed in cooperation with students of the Steinbeis Hochschule, Institut of Body-Related Therapies, in Berlin, Germany. Here, changes in behavior and selfrating of students of the targeted age group are recorded with the help of survey evaluations. Given that the study is still ongoing, the results can only be rated as preliminary.

Former observations have shown that respectfully performed and received touching result in improved composure (posture) and improved school performance. In addition, assessments by teachers allow the conclusion of positive effects-particularly concerning social behavior in the classroom. Furthermore, some of the observed students had overall improvement of results in all researched parameters, especially in coping with stress and regarding the ability to concentrate.*

\section{PERSPECTIVE}

The Samurai School Program is already being practiced in schools of several nations. Next to the German-speaking countries (Germany, Austria, and Switzerland), schools in The Netherlands, Great Britain, Hungary, and Japan (Figs. 7 and 8) have also introduced the program. As noted in the Introduction, at the 2015 AAMA Annual Symposium, the program was introduced in a U.S. context for the first time.

In the meantime, even different non-school institutions have adopted and adapted the Samurai School Program. This

*Project with students of Steinbeis-Hochschule Berlin, Institute for Body-Related Therapies. (Course of studies: Bachelor of Science in Complementary Therapy with the special subject Shiatsu). 
was the reason for the current authors to summarize the different programs under the general term Samurai Program.

The German Child Protection League (Kinderschutzbund), the German Youth Red Cross (Jugendrotkreuz), as well as the German Sports Association (Deutsche Sportbund), for example, have tailored the Samurai Program to their needs. In 2013, the school version of the program was adapted for preschool children (ages 3-6) and applied in a German kindergarten for the first time by using ageappropriate methods in verse form.

Not only children in kindergarten or preschool benefit from Kooko's and Hanako's treatment program. Seniors also benefit from elements of this program. Therefore, the Samurai Program has also been established in retirement homes (Fig. 9). Yet, in this context, completely different conditions have to be taken into account (e.g., interaction with elders suffering from dementia or immobility). Also of high importance is the consideration of what the actual demands are and which exercises the residents are physically able to perform themselves. Accordingly, cooperation with a dementia consultant resulted in a project called "Samurai Shiatsu - Moving and Being Moved for Seniors." 6

\section{DISCUSSION}

The Samurai School Program is intended to "back up" students-literally and figuratively-in school. Many behavioral issues such as being restless, having attention and concentration problems, lacking respect, and lacking the ability to work in a team, appear to be indicative of insufficient development of perception. In particular, body perception plays a fundamental role.

The simple and little time-consuming application of the Samurai School Program seems to be attractive to students of all kinds of cultural backgrounds. Through modifications, this program could be extended for other work areas as well.

\section{CONCLUSIONS}

With its many application possibilities, the Samurai Program facilitates high efficacy with little investment of time and funds. The amount of participant engagement leads to a high degree of compliance.
Because the content is embedded in a story, the playful nature of participants is activated and engaged. Thereby, a certain lightness in acting evolves, which opens up space to gain the courage to try something new. Experiencing that mistakes are part of the learning process and opening up to new opportunities shows participating students that they are not necessarily negative but also carry the potential to grow. The Samurai School Program impresses students with its simplicity in structure without being superficial, which allows for a broad area of application. Visit www.samuraishiatsu.de or www.samurai-shiatsu.co.uk for more information regarding the Samurai School Program.

\section{AUTHOR DISCLOSURE STATEMENT}

No competing financial interests exist.

\section{REFERENCES}

1. Wernicke T, Kalbantner-Wernicke K. Acupuncture for children using the Shōnishin Method regarding developmental physiology [In German]. Dt Ztschr Akup. 2009;52(3):19-22.

2. Pantzer P. Samurai, The Knights of the Far East [in German]. In: Kalbantner-Wernicke K, Wernicke T. Kooko, The Little Samurai [in German]. München: Kiener; 2014:108-111.

3. Kalbantner-Wernicke K, Wernicke T. Samurai-Shiatsu-with Shiatsu Fit for School. München: Kiener; 2014.

4. Seewald J. Motion models and their conceptions of man in different approaches of psychomotricity [sic] [in German]. Motorik. 1998;21(4):151-158.

5. Berthold F, Thierbach P. About physical resilience of the musculoskeletal system from a sports medicine point of view [in German]. Med Sport. 1981;21:165.

6. Wernicke T, Kalbantner-Wernicke K. Samurai ShiatsuMoving and Being Moved for Seniors [in German]. München: Kiener; 2013.
Address correspondence to: Thomas Wernicke, $M D$ Alte Dorfgaße 13 D-65239 Hochheim Germany

E-mail: tw@therapeuticum.de 